\title{
Unusual behavior of quiet-time zonal and vertical plasma drift velocities over Jicamarca during the recent extended solar minimum of 2008
}

\author{
Ângela M. Santos ${ }^{1}$, Mangalathayil A. Abdu ${ }^{1,2}$, Jonas R. Souza ${ }^{1}$, Inez S. Batista ${ }^{1}$, and José H. A. Sobral ${ }^{1}$ \\ ${ }^{1}$ Divisão de Aeronomia, Instituto Nacional de Pesquisas Espaciais, São José dos Campos, 12227-010, São Paulo, Brazil \\ ${ }^{2}$ Instituto Tecnológico de Aeronáutica (ITA), DCTA, São Jose dos Campos, Brazil \\ Correspondence to: Ângela M. Santos (angela.santos@inpe.br)
}

Received: 20 June 2017 - Revised: 2 September 2017 - Accepted: 25 September 2017 - Published: 10 November 2017

\begin{abstract}
The influence of the recent deep and prolonged solar minimum on the daytime zonal and vertical plasma drift velocities during quiet time is investigated in this work. Analyzing the data obtained from incoherent scatter radar from Jicamarca $\left(11.95^{\circ} \mathrm{S}, 76.87^{\circ} \mathrm{W}\right)$ we observe an anomalous behavior of the zonal plasma drift during June 2008 characterized by lower than usual daytime westward drift and its early afternoon reversal to eastward. As a case study the zonal drift observed on 24 June 2008 is modeled using a realistic low-latitude ionosphere simulated by the Sheffield University Plasmasphere-Ionosphere Model-INPE (SUPIMINPE). The results show that an anomalously low zonal wind was mainly responsible for the observed anomalous behavior in the zonal drift. A comparative study of the vertical plasma drifts obtained from magnetometer data for some periods of maximum (2000-2002) and minimum solar activity $(1998,2008,2010)$ phases reveal a considerable decrease on the E-region conductivity and the dynamo electric field during 2008. However, we believe that the contribution of these characteristics to the unusual behavior of the zonal plasma drift is significantly smaller than that arising from the anomalously low zonal wind. The SUPIM-INPE result of the critical frequency of the F layer ( $f_{o} \mathrm{~F} 2$ ) over Jicamarca suggested a lower radiation flux than that predicted by solar irradiance model (SOLAR2000) for June 2008.
\end{abstract}

Keywords. Ionosphere (equatorial ionosphere)

\section{Introduction}

The impacts of the recent deep and prolonged solar minimum on the electron density, temperature, spread F, and total electron content, as well as the vertical and zonal plasma drifts, over the equatorial and low-latitude ionosphere have been studied using different types of observational data, such as digisondes (Liu Libo et al., 2011; Candido et al., 2011; Chuo et al., 2013; Solomon et al., 2013; Narayanan et al., 2014), satellites (Solomon et al., 2011; Huang et al., 2010, 2012; Chuo et al., 2013; Fejer et al., 2013) and incoherent scatter radar (Aponte et al., 2013; Kotov et al., 2015; Santos et al., 2016a). During the period of June 2008 the mean monthly F10.7 radio index reached an extremely low value of $\sim 65.7 \times 10^{-22} \mathrm{~W} \mathrm{~m}^{-2} \mathrm{~Hz}^{-1}$, which represented a solar extreme ultraviolet (EUV) irradiance that was lower than during previous solar cycles. Heelis et al. (2009) and Liu et al. (2012) reported the contraction of the ionosphere during this period. Solomon et al. (2010) showed that during 20072009 , the terrestrial temperature was cooler and the thermosphere was lower in density than expected. They also found that during 2008-2009, the mean thermospheric density were $29 \%$ lower than the solar cycle 22/23 minimum in 1996.

Some authors have analyzed the behavior of the electric fields and plasma drifts during this abnormally quite solar minimum period. Huang et al. (2010), for example, investigated the longitudinal and seasonal variations in the zonal drift and ion density measured by the DMSP (Defense Meteorological Satellite Program) satellite during the period of 2007-2008. They found that depending on the season, the longitudinal structure of the equatorial ionosphere ion density and the eastward drift velocity could present a wave- 
4 pattern during the equinox, a wave- 3 pattern during the northern summer and a wave- 2 pattern in the northern winter. They pointed out that the neutral winds can also play a crucial role in the variations in the ion density and velocity in the equatorial ionosphere. In addition, they also showed that the degree of longitudinal variation in the eastward zonal drift is anticorrelated with solar activity, being smaller during solar maximum and larger during solar minimum. On the other hand, Stoneback et al. (2011) investigated the longitudinal and seasonal variations in the equatorial vertical drift during 2008-2010 using the ion velocity meter (IVM) data obtained on board the C/NOFS (Communication/Navigation Outage Forecasting System) satellite. Contrary to what is expected, they found downward drifts in the afternoon and upward drifts near midnight. A possible enhancement on the semidiurnal tide in low-latitude region was initially suggested as responsible for this unusual behavior of the vertical drift. Rodrigues et al. (2015) did not observe this same characteristic in the daytime equatorial ionospheric vertical drifts as obtained from $150 \mathrm{~km}$ echoes over Jicamarca. As explained by them, the magnetic field lines that pass at $150 \mathrm{~km}$ altitude over the magnetic equator do not reach very far in latitude, so that the semidiurnal patterns similar to those found by Stoneback et al. (2011) were not observed in the $150 \mathrm{~km}$ echo drifts.

Using measurements from C/NOFS, Fejer et al. (2013) presented a study on the seasonal and longitudinal dependence of the quiet-time equatorial average zonal drifts during the period between 2008 and 2011. They noted a strong longitudinal variation in the zonal drift mainly in the American sector during the solstices. It was shown that while in the eastern hemisphere the longitudinal dependence is largely season independent, in the western hemisphere the longitudinal dependence changes considerably with season probably due to the large magnetic declination that characterize this region and thermospheric wind effects. Another interesting point observed by Fejer et al. (2013) was that the evening reversal time of the zonal drift to east $(\sim 17: 00 \mathrm{LT})$ was nearly independent of the longitude during the equinox, but during the winter solstice the reversal occurred before 16:00 LT in the longitude sector between 210 and $360^{\circ}$. Furthermore, the results presented by them revealed a peculiarity about the interval in which the daytime equatorial F-region zonal drift was westward in winter solstice. This interval was found to be $\sim 9 \mathrm{~h}$ in the longitudes between 240 and $285^{\circ}$, whereas at other longitudinal sectors this interval was $\sim 11 \mathrm{~h}$. This implies that, while the reversal of the drift to west in the early morning hours occurred at a later local time $(\sim 07: 00 \mathrm{LT})$, the afternoon reversion of the drift to east occurred at an earlier local time $(\sim 15: 30 \mathrm{LT})$ in these regions. The zonal plasma drifts derived from the Vector Electric Field Investigation (VEFI) measurements on board the C/NOFS satellite during the June solstice of 2008 was investigated by Pfaff et al. (2010). They reported average values of $5-15 \mathrm{~m} \mathrm{~s}^{-1}$ between 07:00 and 09:00 LT and a maximum drift to west of $\sim 25 \mathrm{~m} \mathrm{~s}^{-1}$ at $\sim 13: 00 \mathrm{LT}$. In this case, the reversal of the drift in the afternoon occurred at about 16:30 LT.

Santos et al. (2016a) investigated the ionospheric plasma drifts during the low-solar-activity period of 2008. They showed that an extra ionization in the nighttime E region can have a significant impact on the zonal plasma drift during a disturbed period and suggested that the sporadic $E$ layers that they observed (around 100-130 km) could be considered as strong evidence for extra ionization due to energetic particle precipitation leading to the development of Hall electric field that modified the zonal drift. The present study concerns the earlier eastward reversal (in the afternoon) of the zonal plasma drift observed during the daytime on 24 June, which was under magnetic quiet condition unlike the disturbed night condition (of the same day) that was analyzed by Santos et al. (2016a). In another investigation by Santos et al. (2016b), the sporadic layer was observed at the moment when the ionospheric plasma bubble over São João do Cariri, Brazil, was drifting westward instead of eastward. The formation mechanism of these layers over low and equatorial latitudes has been explained by Abdu et al. (2013). However, more investigations are necessary in order to further explain the conditions, besides those surrounding the disturbance time sporadic E-layer formation, that could directly or indirectly influence the quiet daytime zonal plasma drift of the equatorial $\mathrm{F}$ layer.

In this work, we will present a study on the anomalous behavior of the zonal drift over Jicamarca during the month of June 2008 within the extended solar minimum period. It was observed that the afternoon reversal of the zonal drift to east occurred around $2 \mathrm{~h}$ earlier than expected. At the same time, other important peculiarities were detected in the ionosphere, for example an anomalous behavior of the $f o \mathrm{~F} 2$ parameter over Jicamarca. Our results suggest considerably weakened E-region dynamo as well as corresponding reduced zonal wind, which may be responsible for the weak westward zonal drift during the day and, consequently, for the early reversal of the drift to eastward in the afternoon time.

\section{Data analysis}

The vertical and zonal drift data during 24 June 2008 were collected by the incoherent scatter radar (ISR) operated at Jicamarca $\left(11.95^{\circ} \mathrm{S}, 76.87^{\circ} \mathrm{W}\right)$, Peru. The vertical drift velocities calculated using magnetometer data from Jicamarca and Piura during some days of solar minimum (1998, 2007, $2008,2010)$ and maximum (2000-2002) years were also considered in order to clarify our understanding on the nature of the daytime zonal drift observed during the specific event of 24 June 2008. The drifts data of Jicamarca used in this work can be obtained from the website http: //cedar.openmadrigal.org. SUPIM-INPE was used to simulate the low-latitude ionosphere used in the calculation of the zonal drift. Furthermore, the $f o$ F2 parameter (F2-layer criti- 
cal frequency) over Jicamarca during the time in which the anomalous behavior in zonal drift was observed will also be briefly discussed here.

\subsection{SUPIM-INPE model}

The SUPIM-INPE model is an important tool used in this study in order to calculate some parameters that will be discussed in the results section, such as the zonal plasma drift, the field-line-integrated parameters required to evaluate the vertical electric field and the F2-layer critical frequency over Jicamarca. For the behavior of the equatorial and low-latitude ionosphere to be realistically represented, this model solves the equations of continuity, motion, and energy balance along the lines of the closed magnetic field. The inputs parameters are the solar ionizing radiation flux, the neutral atmosphere densities and temperatures, the neutral winds, and the vertical plasma drifts. The EUV fluxes were obtained from the SOLAR2000 model (Tobiska et al., 2000). The neutral atmosphere densities and temperature were represented by the NRLMSISE-00 (Picone et al., 2002) and the neutral wind velocity was obtained from horizontal wind model HWM93 (Hedin et al., 1996). The vertical plasma drifts were those measured by the Jicamarca incoherent scatter radar. The output parameters provided by the model are concentrations and temperatures of the electrons and of the different ionic species as a function of height, latitude and local time. Using the E- and F-region densities the field-line-integrated Hall and Pedersen conductivities are then calculated. More details about the SUPIM model can be found in Bailey and Balan (1996). SUPIM-INPE is a new version of the original SUPIM model that was updated to extend its lower boundary limit of calculation from its original 120 to $90 \mathrm{~km}$. This modification was necessary to enable calculation of fieldline-integrated conductivity of the entire ionosphere (Souza et al., 2010, 2013).

\section{Results and discussions}

\subsection{The zonal plasma drift}

Figure 1 shows, from top to bottom, (a) the auroral electrojet $\mathrm{AU}$ and $\mathrm{AL}$ indices, (b) the ISR vertical $\left(V_{z}\right)$ and (c) the zonal plasma drifts $\left(V_{y}\right)$ over Jicamarca. The quiettime patterns of these drifts were obtained using the empirical models of Scherliess and Fejer (1999) for $V_{z}$ and Fejer et al. (2005) for $V_{y}$ and are also represented (by blue curves) in panels (b) and (c), respectively. These models were constructed using extensive databases from incoherent scatter radar observations made at the Jicamarca Radio Observatory (Fejer et al., 2005) and a combination of Jicamarca incoherent scatter radar data and ion drift meter data obtained from the Atmospheric Explorer-E satellite (Scherliess and Fejer, 1999). During most of this day the auroral activity was nearly absent, and the vertical and zonal drifts pre- sented a behavior very close to that of quiet days. Starting from 13:30 LT a great discrepancy between the observed and quiet-time model zonal drift can be noted (panel c). As delineated by the shaded area, the reversal of the drift to east on this day occurred $2 \mathrm{~h}$ earlier than its typical (average) reversal time on the quiet day represented by the model drift, as indicated by the red arrows. A weak storm activity began by $\sim$ 18:00 LT. In this paper, the discussions will be limited only to the drift variations during the period before the beginning of the storms, that is, before $\sim 18: 00 \mathrm{LT}$.

A preliminary discussion about the earlier reversal of the zonal drift to east was made by Santos et al. (2016a). The zonal plasma drift was calculated using the expression $V_{y}=$ $E_{z} / \boldsymbol{B}$, in which the vertical electric field $E_{z}$ is given by Eccles (1998):

$E_{z}=\frac{\sum H}{\sum P}\left(\boldsymbol{B} V_{z}-\boldsymbol{B} U_{z}^{H}\right)-\boldsymbol{B} U_{y}^{P}$,

where $B$ is the total magnetic field intensity at the field line apex, $\sum H$ and $\sum P$ are the field-line-integrated Hall and Pedersen conductivities, respectively. $U_{y}^{P}$ is the field-lineintegrated and Pedersen conductivity-weighted zonal wind velocity, $U_{L}^{H}$ is the Hall conductivity-weighted and fieldline-integrated meridional neutral wind velocity perpendicular to magnetic field $\boldsymbol{B}$, and $V_{z}$ is the vertical plasma velocity in the equatorial plane.

The results from SUPIM-INPE were used to calculate the zonal plasma drift based on $E_{z}$ obtained from Eq. (1) and considering three situations. (1) Only the term related to the field-line-integrated and Pedersen conductivity-weighted zonal wind velocity $\left(U_{y}^{P}\right)$ was used in the calculation of the zonal drift, (2) the zonal drift was calculated using the "Hall conduction" term as given by $-\frac{\sum H}{\sum P}\left(V_{z}-U_{z}^{H}\right)$, and (3) the effects from the zonal wind and the Hall conduction were considered together. The results for these three cases are presented in Fig. 2 (see also Santos et al., 2016a). The dashed and dotted curves in panel (b) represent the first and the second case, respectively, while the solid blue curve in panel (c) corresponds to the third case. It is interesting to observe that similarly to the zonal drift from Fejer et al. (2005) in panel (c) of Fig. 1, the results of the modeled zonal drift in case 3 (solid blue line, panel $\mathrm{c}$ of Fig. 2) also presents a delay of $\sim 2 \mathrm{~h}$ in the reversal of the drift to east (as indicated by the red arrows) when compared to observational data (black line). Based on these calculation Santos et al. (2016a) showed that this earlier reversal in the observational data could be explained in large part by the zonal wind that behaved anomalously during this period. This conclusion is further reinforced in this study since we note that the impacts of the zonal wind in the definition of the zonal drift appear to be more important until 20:00 UT when compared with the contribution of the term related to the vertical drift as shown by the results in panel (b) of Fig. 2. Although the contribution of zonal wind appears to have been a fundamental factor in the earlier re- 


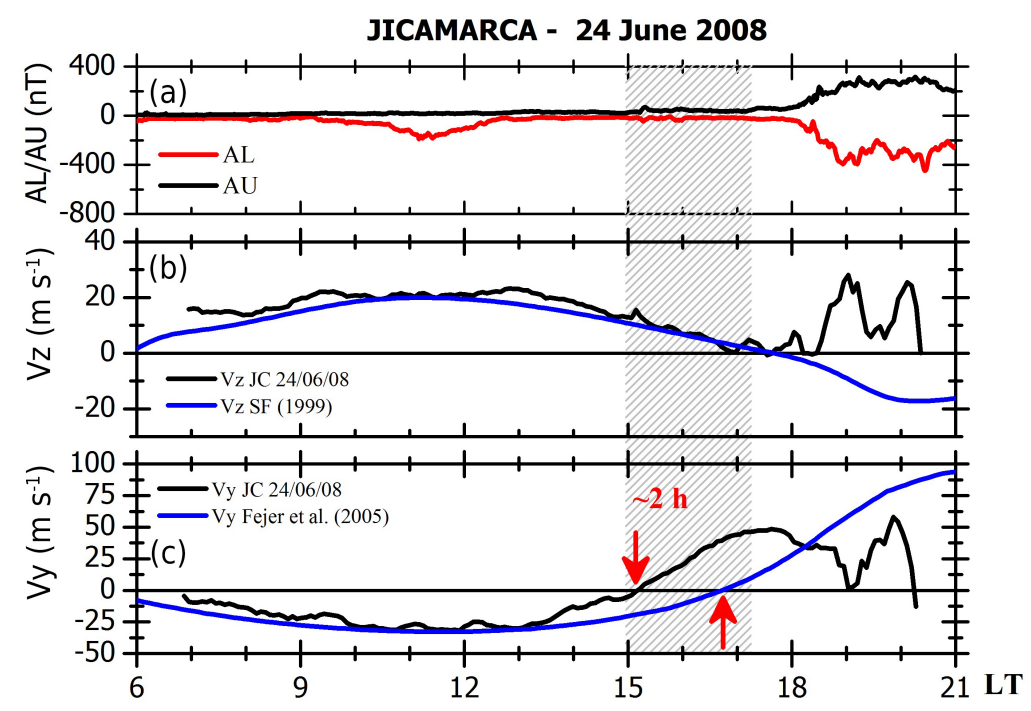

Figure 1. (a) Values for AL/AU with time resolution of $1 \mathrm{~min}$ and (b, c) the ionospheric vertical drift $\left(V_{z}\right)$ and zonal drift $\left(V_{y}\right)$ measured by the ISR at Jicamarca on 24 June 2008. The vertical and zonal plasma drifts as per the models by Scherliess and Fejer (1999) (for $V_{z}$ ) and Fejer et al. (2005) (for $V_{y}$ ) are represented by the blue lines in panels (b, c). The shaded area and the red arrows highlight the earlier reversal of the zonal drift to east when compared to the model.

versal of $V_{y}$ during this day, we will show below that the peculiar behavior of $V_{z}$ in 2008 (see shaded area in panel a) was another important parameter that needs to be considered in the context of this discussion to fully explain the effect.

Figure 3 shows some cases of zonal drift variations over Jicamarca representing different solar activity minimum epochs and illustrates the anomalous behavior of the zonal drift during the extended solar minimum in 2008. Two interesting characteristics can be noted in these results. (1) The afternoon reversal of the drift to east occurs earlier in 2008 than in all the other years. While in 1997 the reversal occurred at $\sim$ 17:00 LT, in 2008 this characteristic was observed mostly before 15:00 LT, that is, about $2 \mathrm{~h}$ earlier. (2) The zonal drift intensity near midday was the weakest during 2008. It is possible to note that while in 2008 the $V_{y}$ attained a value of $\sim-25 \mathrm{~m} \mathrm{~s}^{-1}$ at $\sim 12: 00 \mathrm{LT}$ (blue dotted horizontal line), in 1997 it was $\sim-50 \mathrm{~ms}^{-1}$. For July 2010, the year in which the solar activity is still low, but with a tendency of increase, the drift values during the day oscillated around $\sim-50 \mathrm{~m} \mathrm{~s}^{-1}$, and the reversal occurred after 15:00 LT.

In order to help understand the anomalous behavior of the zonal drift/vertical electric field over the Peruvian sector during the last solar minimum period, the vertical $\boldsymbol{E} \times \boldsymbol{B}$ drift calculated according to the methodology proposed by Anderson et al. (2002) was used to investigate the impacts of $V_{z}$ in the decrease in the Hall conduction term $\left(-\frac{\sum H}{\sum P}\left(V_{z}-U_{z}^{H}\right)\right)$ and consequently in the earlier reversal of $V_{y}$. The decrease rate in $V_{z}$ from $\sim 13: 00 \mathrm{LT}$, as illustrated by the shaded area in panel (a) of Fig. 2, which is faster than in other years (as will be shown below), appears to be another important consequence of the deep solar mini- mum activity during this year. Therefore, we believe that an understanding of how $V_{z}$ was influenced by the solar activity during this and other periods will be very relevant to evaluate the real importance of the Hall conduction term in the earlier reversal of the $V_{y}$ in June 2008. For this analysis to be possible, we will analyze $V_{z}$ during different periods of solar activity. Figure 4 shows averages with SD of vertical drifts over Jicamarca for quiet days during some minimum solar activity epochs. We use the months of July 1998 at solar cycle 22, May 2007 and June 2008 at solar cycle 23, and June 2010 at solar cycle 24. Comparing the average behavior of the drift in 2008 with the other periods, we can note that the maximum value of the drift during the day is very similar at all solar cycles. On the other hand, the decrease rate of the drift from 13:00 LT seems to be more pronounced in 2008 than in the other periods. In fact, we can observe that the drift value at 15:00 LT (indicated in the figure by a vertical dotted line) is the smallest in 2008 (the period in which the zonal drift reversed to east on 24 June) in comparison with all the other years evaluated. While in 2008 the drift attained a value of $7 \mathrm{~m} \mathrm{~s}^{-1}$ at this time, in 1998 the value was $\sim 11.1 \mathrm{~m} \mathrm{~s}^{-1}$. In addition, it is possible to observe that, only in 2008 , the vertical drift $\left(V_{z}\right)$ attained negative values before 16:30 LT (indicated by the blue arrow). The $V_{z}$ deduced from magnetometer data over Jicamarca for almost every day of June 2008 is presented in Fig. 5a, in which we note (within the shaded area) that the negative value of the vertical drift was reached even before the 16:30 LT during some days. On 21 June, the $V_{z}$ reversal occurred at about 14:15 LT, a very different behavior than expected. Figure $5 \mathrm{~b}$ shows the average $V_{z}$ from digisonde data over the equatorial site São Luís, 


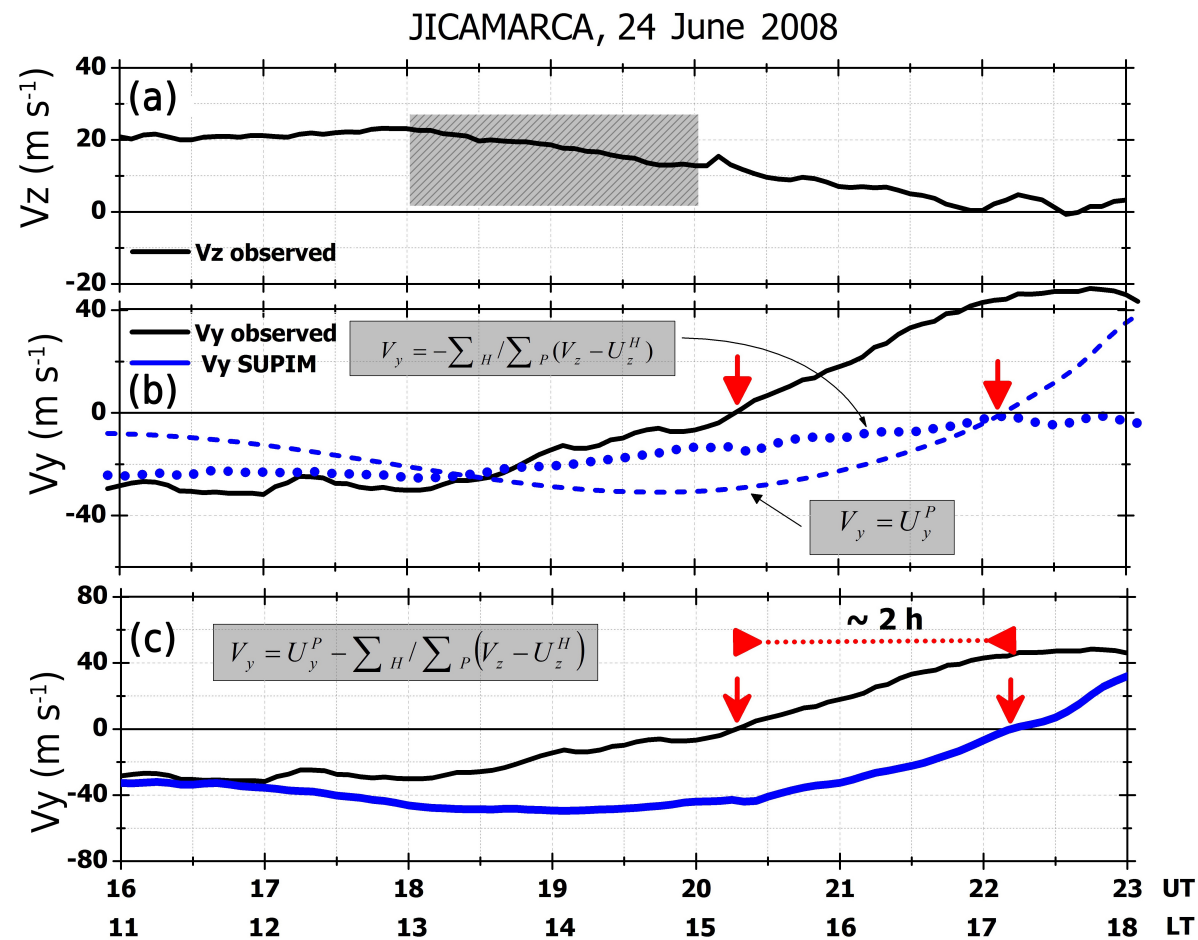

Figure 2. (a) The measured vertical and (b, c) zonal plasma drifts during 24 June 2008. The calculated zonal drifts for different conditions are also presented as dotted and dashed blue curves in panel (b) and solid blue curve in panel (c). The solid black curves in panels (b, c) are the observed zonal drift. The shaded area and the red arrows indicate some important points that are discussed in the text.

Brazil, for some days of June 2009 and June 1996, calculated as $\mathrm{dhF} / \mathrm{d} t$ from true heights at specific plasma frequencies of 4 and $5 \mathrm{MHz}$. It is important to mention that the São Luis time zone is ahead of Jicamarca by $\sim 2 \mathrm{~h}$. In the absence of digisonde data for 2008, we use data from 2009 to represent the last solar minimum. It is known that the ionosphere can present large variability from year to year, primarily during this extremely low solar activity. But, in this case, the mean values of F10.7 for June of both years, for example, was very near, being $\sim 65.7 \times 10^{-22} \mathrm{~W} \mathrm{~m}^{-2} \mathrm{~Hz}^{-1}$ for 2008 and $68.6 \times 10^{-22} \mathrm{~W} \mathrm{~m}^{-2} \mathrm{~Hz}^{-1}$ for 2009 , supporting the idea of similar ionospheric behavior in 2008 and 2009. Similarly to Jicamarca, the $V_{z}$ over the Brazilian region also presented an anomalous decrease for this last solar minimum period between $\sim 14: 40$ and $\sim 17: 15 \mathrm{LT}$. As we used this result only with a qualitative purpose, we believe that the correction of the vertical drift due to the daytime photochemical effects was not necessary in this case. As can be seen in panel $\mathrm{c}$ of Fig. 5, the difference between the monthly average F-layer height (considering the mean of heights at 4 and $5 \mathrm{MHz}$ ) during 1996 and 2009 was almost constant during the entire period analyzed (except at $\sim 17: 40 \mathrm{UT}$ ), with the F-layer height in 2009 being smaller than in 1996. It is known that below $300 \mathrm{~km}$ the recombination effect produces an apparent upward drift (Bittencourt and Abdu, 1981), so that the vertical drift determined as $\mathrm{dhF} / \mathrm{d} t$ is an overestimation when it is upward, whereas it is an underestimation when it is downward. Based on this reasoning, the correction for $V_{z}$ (to get the real drift), in the shaded area in Fig. $5 \mathrm{c}$, will be larger for 2009 (since the $h \mathrm{~F}$ is smaller) than it will be for the 1996 (where the $h \mathrm{~F}$ is higher) thereby enhancing difference in the real drift between the two epochs, during much of the period of interest here. The variation in the F-layer height during the periods of 1996 and 2009 for Brazilian region presented in Fig. 5c is in agreement with the results of Liu et al. (2012), who showed that the F2-layer peak height ( $h m \mathrm{~F} 2$ ) over Jicamarca in June solstice was lower in 2008-2009 when compared to 1996-1997, for both daytime and nighttime. Those results reveal that the upper atmosphere ion temperature was lower during the deep minimum of 2008-2009 as compared to other minima which explained the lower values of $h m \mathrm{~F} 2$ for these epochs. The correspondingly lower thermospheric density might be responsible for a weaker solar thermal tide and therefore a weaker zonal neutral wind in the thermosphere.

The vertical drift over São Luis in Fig. 5b showed abnormally low values during the same local time (15:0017:00 LT) when it was also abnormally low over Jicamarca in June 2008 (as can be noted in Fig. 4). This weaker and sometimes downward vertical drift during the daytime for an equatorial region during this last solar minimum was also discussed by Stoneback et al. (2011) and Pfaff et al. (2010). 

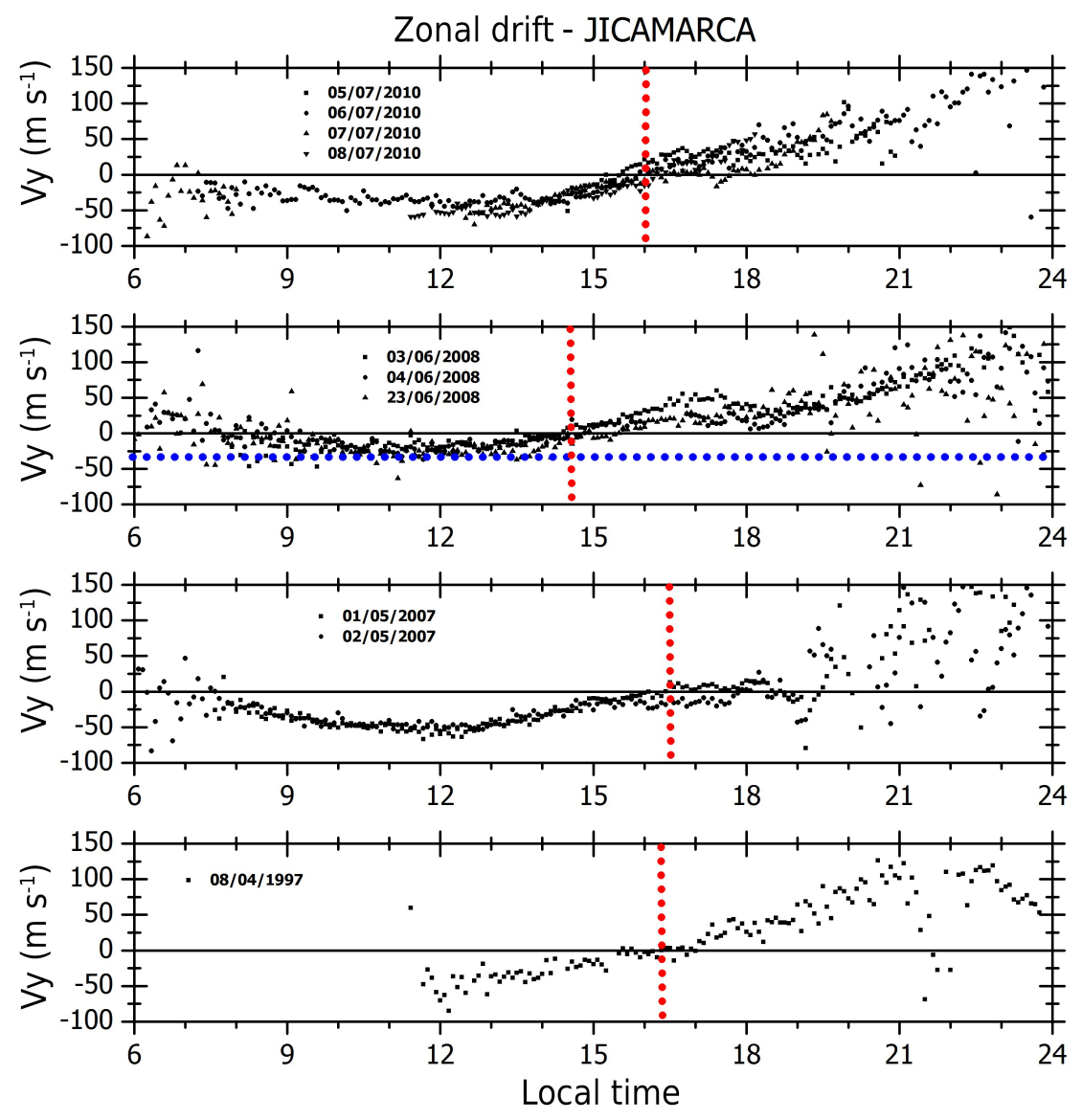

Figure 3. The zonal plasma drifts for different solar minimum activity epochs. The vertical dotted lines indicate times of the reversal of the drift to east in the afternoon, which, during June 2008, occurred earlier when compared with other solar minimum periods. The horizontal dotted line in the 2008 plot indicates the low intensity of the zonal drift during this period.

Stoneback et al. (2011) suggested that this characteristic was caused by an increase in the semidiurnal tide in the $\mathrm{E}$ region. Pfaff et al. (2010) suggested a decrease in the intrinsic F-region dynamo in the June solstice considering the weaker and more variable electric fields observed by VEFI on board of CNOFs. During daytime the E-region dynamo electric field driven by tidal wind modes is normally responsible for the control of the ionospheric F-layer phenomena due to strong coupling that exists between these two regions through the magnetic field line mapping of large-scale (dynamo) electric field. The vertical plasma $(\boldsymbol{E} \times \boldsymbol{B})$ drift (as well as the plasma fountain) in the $F$ layer is driven by the dynamo zonal electric field mapped from the $\mathrm{E}$ layer. Therefore, the decrease in the daytime vertical drift found in our results (Figs. 2 and 4) is due to a decrease in the E-layer dynamo, which has been attributed to an increase in semi diurnal tide (as suggested by Stoneback et al., 2011). (A discussion on the mechanism operative in the modification of tidal modes is beyond the scope of this paper.) The point of interest here concerns the decrease in the contribution to the vertical electric field (zonal drift) arising from the first term of Eq. (1) due to a decrease in the vertical drift. As a result of the diminished role of this term the contribution from zonal wind term dominates. This is how we can justify the adjustment in the zonal wind (towards a weaker zonal wind) that was necessary to explain the anomalous behavior of the zonal drift under the given situation. The influence of the external drivers from the magnetosphere and solar wind forcing can be excluded in this case because the period studied here is representative of the solar activity phase with extremely quiet conditions. Thus, we believe that these anomalous features observed in our data may have been caused in part by the decline of the E-region dynamo. In this situation, the Fregion winds and the consequent polarization electric fields became dominant in driving the F-region zonal plasma drift.

Figure 6 presents the vertical drift at Jicamarca for some periods of high solar activity. Comparing the general characteristics of these results with the vertical drift for minimum solar activity of Fig. 4, small differences can be noted. However, unlike the drift in 2008 , at all the high solar activity periods (2000, 2001 and 2002) the vertical drift did not reverse to negative values before 17:00 LT. This important feature re- 

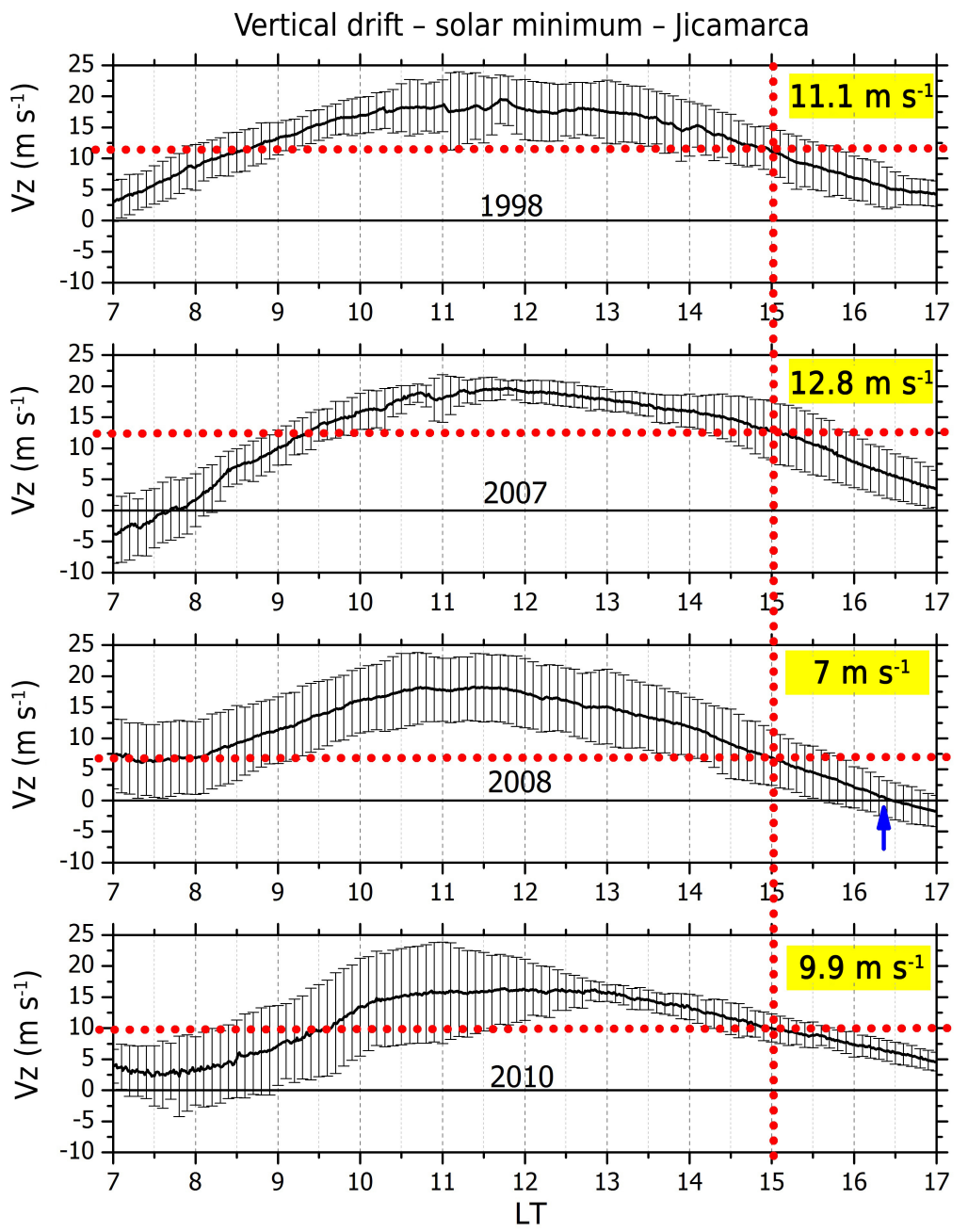

Figure 4. The vertical plasma drifts from magnetometers (Jicamarca-Piura: Jic-Piu) for different periods of solar minimum activity. The horizontal dotted line highlights the intensity of $V_{z}$ at 15:00 LT. The blue arrow indicates that only in $2008 V_{z}$ attained negative values before 17:00 LT.

veals the peculiar nature of the daytime vertical drift/zonal electric field during 2008. It is important to mention that a similar study involving SUPIM-INPE has also been carried out to analyze the zonal drift of 1997 (see Santos et al., 2016a, for more details), which represented a normal solar minimum epoch. The authors showed that the eastward reversal of the drift during 10 April was correctly simulated by the model, without the need to make any adjustments in the zonal wind as in the event of June 2008.

\subsubsection{The F2-layer critical frequency ( $f \circ \mathrm{F} 2)$}

Similar to the zonal drift, the comparison between the modeled and observed $f_{o} \mathrm{~F} 2$ values (representing the F2-layer peak electron density) for 24 June was also performed in this work. This was necessary in order to validate the lowlatitude ionosphere simulated by SUPIM-INPE, which is the basis of the parameters used in the calculations of the field- line-integrated conductivities that were used in the zonal drift calculations. The SUPIM-INPE results on the $f o \mathrm{~F} 2$ variation are the most suited parameter for checking the validity of the model. As previously mentioned by Santos et al. (2016a), some adjustments in the solar irradiance model (SOLAR2000) were necessary in order to obtain a more satisfactory result on the $f o \mathrm{~F} 2$ parameter as explained below with the help of Fig. 7. In Fig. 7 the experimental data of $f o \mathrm{~F} 2$ are indicated by the black line, in which the solid/dotted line segments represent the values of foF 2 measured in the absence/presence of spread F. The first model result is denoted by the blue line (SF1, where SF represents "solar flux"). We can see large differences between observed and modeled results during the entire period analyzed, with $f_{o} \mathrm{~F} 2$ obtained by SUPIM-INPE being smaller than the observational data. Since the vertical drift used as input parameter in the model (see Fig. 1, panel b) has been verified to be realistic, and since 


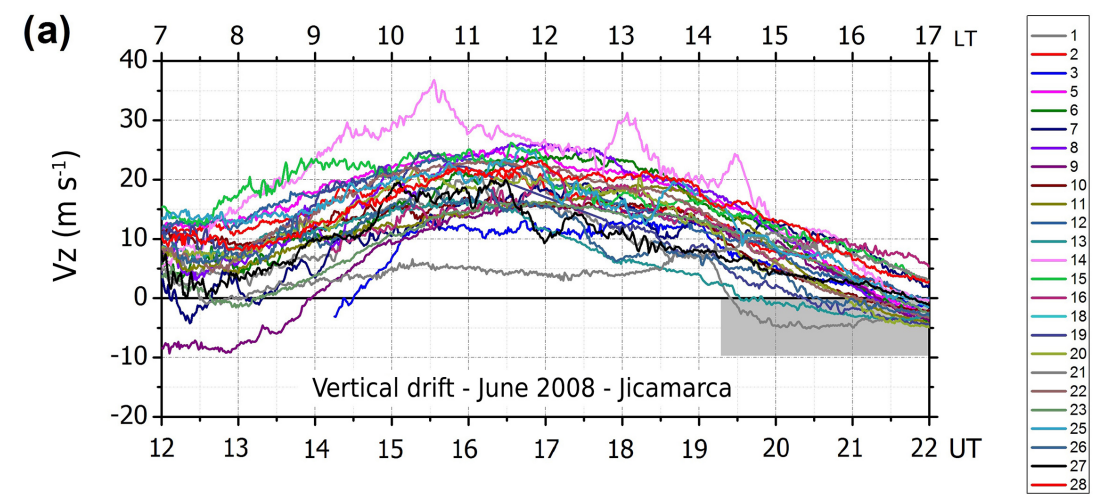

(b)

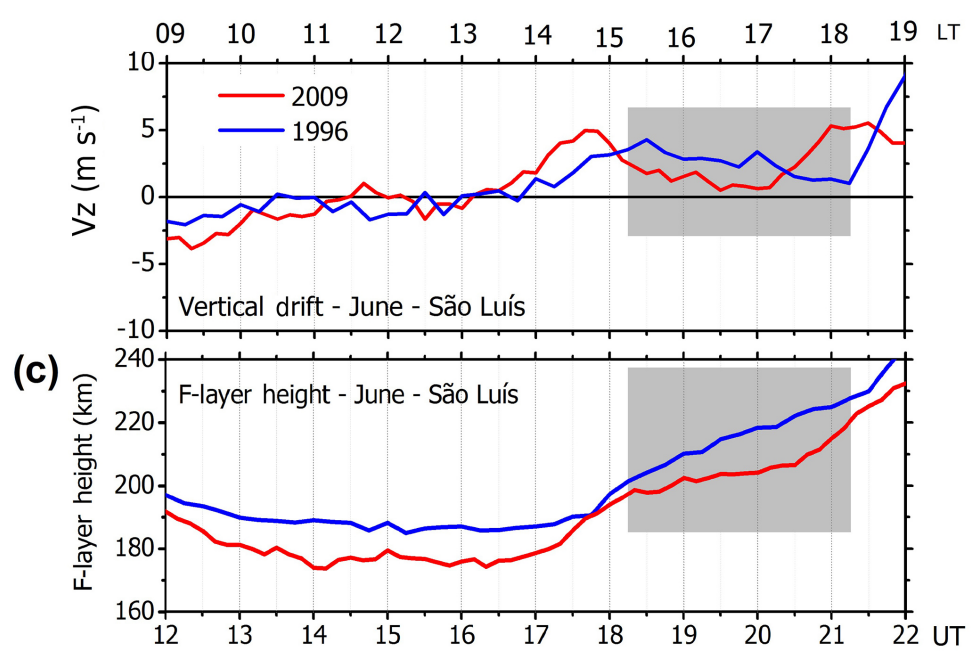

Figure 5. (a) The vertical plasma drifts from magnetometers (Jic-Piu) for almost all days of June 2008. (b) The mean vertical plasma drifts for June (calculated as the average of the drifts at plasma frequencies 4 and $5 \mathrm{MHz}$ ) over São Luis-Brazil during the solar cycle 23 (1996) and solar cycle 24 (2009). (c) The F-layer heights (taken as the mean of the heights at 4 and $5 \mathrm{MHz}$ plasma frequencies) for June 1996 and 2009. The shaded area indicates the anomalous behavior of the vertical drift that is discussed in the text.

the shape of the modeled $f o \mathrm{~F} 2$ variation is nearly the same as that of the observed $f o \mathrm{~F} 2$, it is possible that the large differences between observations and model can be attributed to the solar irradiance model (SOLAR2000) not adequately representing the solar radiation for the period under consideration. This possibility is further reinforced by the fact that the results from the model (using the SF1) were lower since the early hours of the morning, when the dynamical effects are overwhelmed by the contribution from the photoionization.

In order to further investigate whether the solar irradiance model was inappropriate for this time of the extreme solar minimum condition, we used another version of the SOLAR2000 model (SF2) and found again that the results obtained with this new version did not represent the experimental data well, as suggested by the gray line (SF2) in Fig. 7. In this case the values from the model were higher than the experimental data mainly between 12:00 UT (day 24) and 01:00 UT (day 25). Given such discrepant results, we decided to make some adjustments in the solar irradiance (SF2) val- ues in order to reach a reasonable agreement with the observed value of $f o \mathrm{~F} 2$. The resulting model $f o \mathrm{~F} 2$ values obtained using the adjusted solar flux, SF3, are represented by the red line in Fig. 7. An excellent agreement with the observations is obtained (except for some hours after 01:00 UT) when the model is run using the solar irradiance SF2 divided by a factor of 1.35 . We believe that this result, together with the anomalous behavior of the zonal plasma drift, represents a good example of how the basic characteristics of the ionosphere were significantly modified by the factors influenced by the very low solar activity. It is likely that any solar irradiance model that depends in part on the F10.7 index will overestimate the solar EUV flux during the 2008-2009 epochs. In fact, Solomon et al. (2011) discussed experimental evidence that the EUV flux during the 2008-2009 solar minimum was significantly less than the previous solar minimum, varying by factors between 4 and $15 \%$, depending on the spectra/instrument being observed/used. 

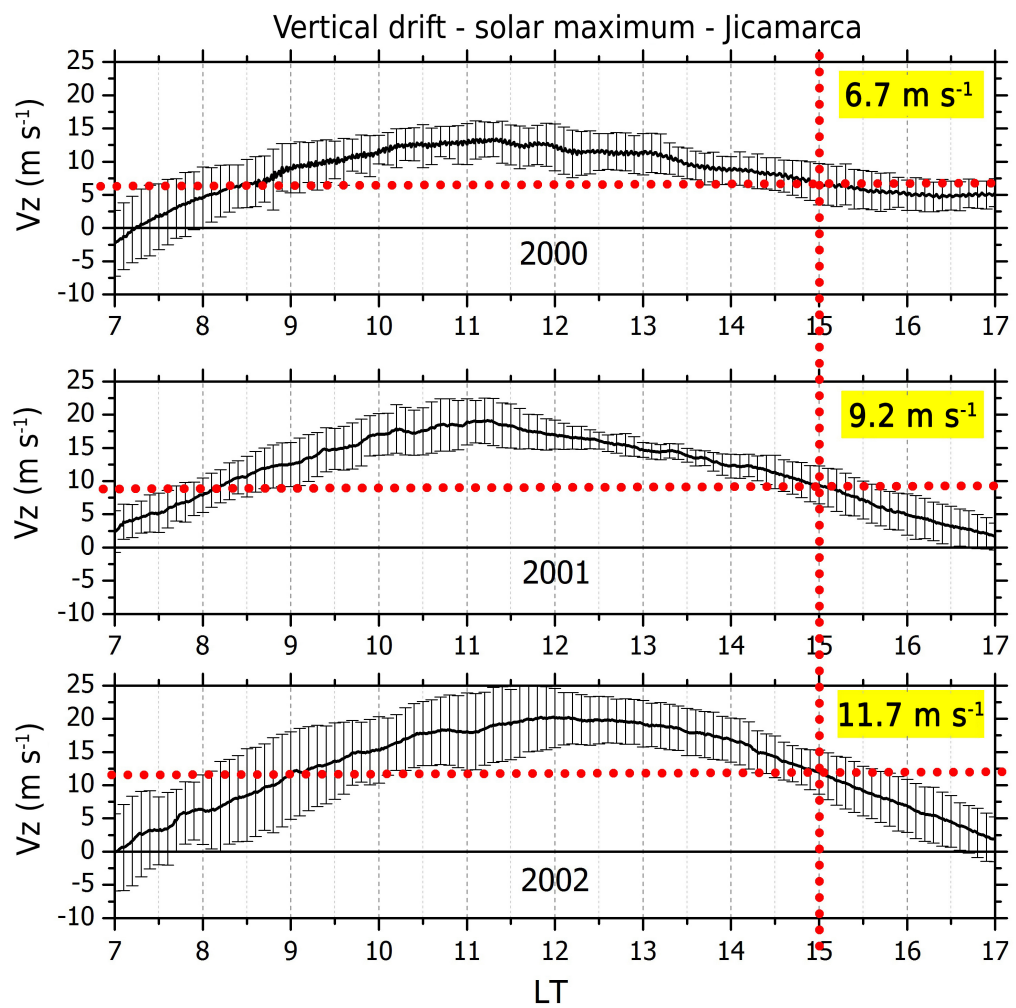

Figure 6. The vertical plasma drifts from magnetometers (Jic-Piu) for different periods of solar maximum activity. The dotted lines highlight the intensity of $V_{z}$ at 15:00 LT.

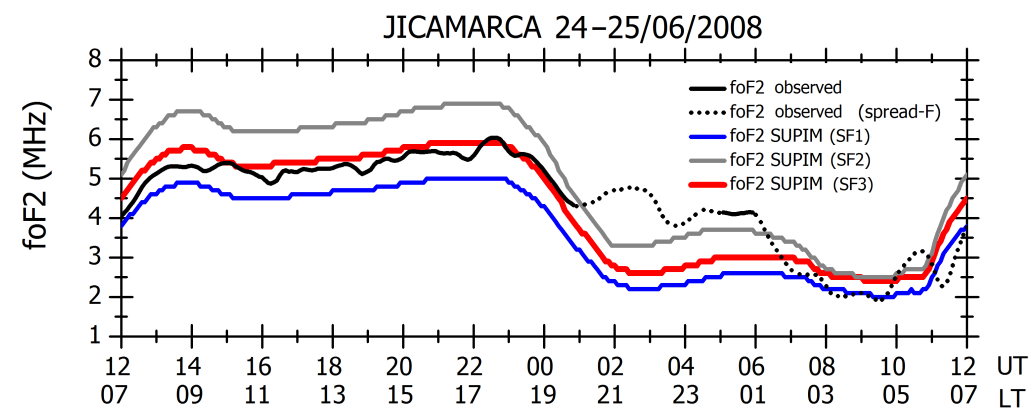

Figure 7. Comparison of critical frequency of the $\mathrm{F}$ layer $(f o \mathrm{~F} 2)$ registered by the digisonde at Jicamarca (black solid curve) and the $f o \mathrm{~F} 2$ modeled by SUPIM-INPE using different adjustments in the solar irradiance model (SOLAR2000). The dotted segment of the black curve indicates the $f o \mathrm{~F} 2$ parameter processed in the presence of spread-F traces.

\section{Conclusions}

The extremely low solar activity of June 2008 produced a remarkable impact on the dynamics of the ionosphere as observed in the ionospheric drifts over Jicamarca (zonal and vertical components) as well as in the electron density. The zonal drift on 24 June reversed to east around $2 \mathrm{~h}$ earlier than such reversal time predicted by the drift model of Fejer et al. (2005) that calculated by SUPIM-INPE based on HWM zonal wind. The zonal drift analyzed for a few other available days in June 2008 also showed earlier eastward re- versal as compared to those of similar day groups examined during other solar activity minimum epochs, thereby confirming the unique nature of the effects due to the extremely low activity period of June 2008. Model calculations of the zonal drift based on a realistic low-latitude ionosphere simulated by SUPIM-INPE showed that the major contribution to the drift arises from the Pedersen conductivity-weighted F-region zonal wind, rather than from E-layer dynamo electric field with associated Hall conduction effect. Our results showed that the beginning of the decrease in the westward zonal drift was coincident with a decrease in the vertical 
drift. The comparative analysis of the mean vertical drift of June 2008 with other periods of solar minimum activity showed that the decrease in the vertical drift between 13:00 and 15:00 LT was more pronounced in 2008 than in other years. Furthermore, our results showed that only in 2008 did the vertical drifts attain negative values before 17:00 LT, thus demonstrating the unusual changes in the zonal electric fields during this period. However, based on the modeling results (as mentioned above) we believe that this anomalous decrease in the vertical drift during the day was not a significant factor; rather, the weaker zonal winds were the dominant factor that contributed to the earlier reversal of the zonal drift during this day. Similar to the results from Jicamarca, the mean vertical drift for June over the Brazilian longitude sector for two periods of solar minimum activity of the solar cycles 22 and 23 also reveals a more pronounced decrease in the vertical drift from São Luís between $\sim$ 18:00 and 20:00 UT (15:00 and 17:00 LT) in 2009 than in 1996. Thus, it appears that the abnormally lower daytime westward zonal drift with its earlier eastward (afternoon) reversal driven by weaker thermospheric zonal wind on the one hand and the abnormally low vertical drift (zonal electric field) driven by weaker E-layer dynamo on the other are two individual aspects of the unique effects arising from the extreme solar minimum period.

The electron density represented here by the $f \circ \mathrm{F} 2$ data has been used to investigate the responses of the ionosphere over Jicamarca to the lower EUV irradiance in the year of 2008. Comparing modeled and observed data, our results suggest that a discrepancy found in the solar irradiance model (SOLAR2000) was responsible for the differences between model calculations and observed data.

Data availability. The auroral indexes and IMF data were obtained from the website http://omniweb.gsfc.nasa.gov/form/omni_ min.html. The digisonde data from Brazil may be acquired by contacting the responsible coordinators at DAE/INPE (Inez S. Batista; e-mail: inez.batista@inpe.br). The drift data of Jicamarca were obtained from the website http://cedar.openmadrigal.org.

Competing interests. The authors declare that they have no conflict of interest.

Special issue statement. This article is part of the special issue "Space weather connections to near-Earth space and the atmosphere". It is a result of the $6^{\circ}$ Simpósio Brasileiro de Geofísica Espacial e Aeronomia (SBGEA), Jataí, Brazil, 26-30 September 2016.

Acknowledgements. Angela M. Santos acknowledges the Fundação de Amparo à Pesquisa do Estado de São Paulo - FAPESP for the financial support under grant 2015/25357-4 and CAPES.
The authors gratefully acknowledge the Jicamarca staff for providing the ionospheric data from IRS, magnetometers, and digisondes. The Jicamarca Radio Observatory is a facility of the Instituto Geofisico del Peru operated with support from the NSF AGS-0905448 through Cornell University.

The topical editor, Ricardo A. Buriti, thanks Igo Paulino and one anonymous referee for help in evaluating this paper.

\section{References}

Abdu, M. A., Souza, J. R., Batista, I. S., Fejer, B. G., and Sobral, J. H. A.: Sporadic E layer development and disruption at low latitudes by prompt penetration electric fields during magnetic storms, J. Geophys. Res.-Space, 118, 2639-2647, https://doi.org/10.1002/jgra.50271, 2013.

Anderson, D., Anghel, A., Yumoto, K., Ishitsuka, M., and Kudeki, E.: Estimating daytime vertical $\mathrm{E} \times \mathrm{B}$ drift velocities in the equatorial $\mathrm{F}$ region using ground-based magnetometer observations, Geophys. Res. Lett., 29, 1596, https://doi.org/10.1029/2001GL014562, 2002.

Aponte, N., Brum, C. G. M., Sulzer, M. P., and Gonzalez, S. A.: Measurements of the $\mathrm{O}+$ to $\mathrm{H}+$ transition height and ion temperatures in the lower topside ionosphere over Arecibo for equinox conditions during the 2008-2009 extreme solar minimum, J. Geophys. Res.-Space, 118, 4465-4470, https://doi.org/10.1002/jgra.50416, 2013.

Bailey, G. J. and Balan, N.: Some modelling studies of the equatorial ionosphere using the Sheffield University Plasmasphere Ionosphere Model, Adv. Space Res., 18, 59-68, https://doi.org/10.1016/0273-1177(95)00901-9, 1996.

Bittencourt, J. A. and Abdu, M. A.: A theoretical comparison between apparent and real vertical ionization drift velocities in the equatorial F region, J. Geophys. Res., 86, 2451-2454, https://doi.org/10.1029/JA086iA04p02451, 1981.

Candido, C. M. N., Batista, I. S., Becker-Guedes, F., Abdu, M. A., Sobral, J. H. A., and Takahashi, H.: Spread F occurrence over a southern anomaly crest location in Brazil during June solstice of solar minimum activity, J. Geophys. Res., 116, A06316, https://doi.org/10.1029/2010JA016374, 2011.

Chuo, Y. J., Lee, C. C., Chen, W. S., and Reinisch, B. W.: Comparison of the characteristics of ionospheric parameters obtained from FORMOSAT-3 and digisonde over Ascension Island, Ann. Geophys., 31, 787-794, https://doi.org/10.5194/angeo-31-7872013, 2013.

Eccles, J. V.: A simple model of low latitude electric fields, J. Geophys. Res., 103, 26699-26708, https://doi.org/10.1029/98JA02657, 1998.

Fejer, B. G., De Souza, J., Santos, A. S., and Pereira, A. E. C.: Climatology of $\mathrm{F}$ region zonal plasma drifts over Jicamarca, J. Geophys. Res., 110, A12310, https://doi.org/10.1029/2005JA011324, 2005.

Fejer, B. G., Tracy, B. D., and Pfaff, R. F.: Equatorial zonal plasma drifts measured by the C/NOFS satellite during the 20082011 solar minimum, J. Geophys. Res.-Space, 118, 3891-3897, https://doi.org/10.1002/jgra.50382, 2013.

Hedin, A. E., Fleming, E. L., Manson, A. H., Schmidlin, F. J., Avery, S. K., Clark, R. R., Franke, S. J., Fraser, G. J., Tsuda, T., Vial, F., and Vincent, R. A.: Empirical wind model for the upper, mid- 
dle and lower atmosphere, J. Atmos. Terr. Phys., 58, 1421-1447, https://doi.org/10.1016/0021-9169(95)00122-0, 1996.

Heelis, R. A., Coley, W. R., Burrell, A. G., Hairston, M. R., Earle, G. D., Perdue, M. D., Power, R. A., Harmon, L. L., Holt, B. J., and Lippincott, C. R.: Behavior of the $\mathrm{O}+/ \mathrm{H}+$ transition height during the extreme solar minimum of 2008, Geophys. Res. Lett., 36, L00C03, https://doi.org/10.1029/2009GL038652, 2009.

Huang, C.-S., Rich, F. J., de La Beaujardiere, O., and Heelis, R. A.: Longitudinal and seasonal variations of the equatorial ionospheric ion density and eastward drift velocity in the dusk sector, J. Geophys. Res., 115, A02305, https://doi.org/10.1029/2009JA014503, 2010.

Huang, C. Y., Roddy, P. A., Sutton, E. K., Stoneback, R., Pfaff, R. F., L. C. Gentile, and Delay, S. H.: Ion-neutral coupling during deep solar minimum, J. Atmos. Sol. Terr. Phys., 103, 138146, https://doi.org/10.1016/j.jastp.2012.11.009, 2012.

Kotov, D. V., Truhlík, V., Richards, P. G., Stankov, S., Bogomaz, O. V., Chernogor, L. F., and Domnin, I. F.: Night-time light ion transition height behaviour over the Kharkiv $\left(50^{\circ} \mathrm{N}, 36^{\circ} \mathrm{E}\right)$ IS radar during the equinoxes of 2006-2010, J. Atmos. Sol.-Terr. Phy., 132, 1-12, https://doi.org/10.1016/j.jastp.2015.06.004, 2015.

Liu, L., Chen, Y., Le, H., Kurkin, V. I., Polekh, N. M., and Lee, C.-C.: The ionosphere under extremely prolonged low solar activity, J. Geophys. Res., 116, A04320, https://doi.org/10.1029/2010JA016296, 2011.

Liu, L., Yang, J., Le, H., Chen, Y., Wan, W., and Lee, C.-C.: Comparative study of the equatorial ionosphere over Jicamarca during recent two solar minima, J. Geophys. Res., 117, A01315, https://doi.org/10.1029/2011JA017215, 2012.

Narayanan, V. L., Sau, S., Gurubaran, S., Shiokawa, K., Balan, N., Emperumal, K., and Sripathi, S.: A statistical study of satellite traces and subsequent evolution of equatorial spread $\mathrm{F}$ based on ionosonde observations over dip equatorial site Tirunelveli, India, Earth Planets. Space, 66, 160, https://doi.org/10.1186/s40623-014-0160-4, 2014.

Pfaff, R., Rowland, D.,Freudenreich, H., Bromund, K.,Le, G., Acuña, M., Klenzing, J., Liebrecht, C., Martin, S., Burke, W. J., Maynard, N. C., Hunton, D. E., Roddy, P. A., Ballenthin, J. O., and Wilson, G. R.: Observations of DC electric fields in the low-latitude ionosphere and their variations with local time, longitude, and plasma density during extreme solar minimum, J. Geophys. Res., 115, A12324, https://doi.org/10.1029/2010JA016023, 2010.

Picone, J. M., Hedin, A. E., Drob, D. P., and Aikin, A. C.: NRLMSISE-00 empirical model of the atmosphere: statistical comparisons and scientific issues, J. Geophys. Res., 107, 1468, https://doi.org/10.1029/2002JA009430, 2002.
Rodrigues, F. S., Smith, J. M., Milla, M., and Stoneback, R. A.: Daytime ionospheric equatorial vertical drifts during the 2008 2009 extreme solar minimum, J. Geophys. Res.-Space, 120, 1452-1459, https://doi.org/10.1002/2014JA020478, 2015.

Santos, A. M., Abdu, M. A., Souza, J. R., Sobral, J. H. A., and Batista, I. S.: Disturbance zonal and vertical plasma drifts in the Peruvian sector during solar minimum phases, J. Geophys. Res.Space, 121, 2503-2521, https://doi.org/10.1002/2015JA022146, 2016a.

Santos, A. M., Abdu, M. A., Souza, J. R., Sobral, J. H. A., Batista, I. S., and Denardini, C. M.: Storm time equatorial plasma bubble zonal drift reversal due to disturbance Hall electric field over the Brazilian region, J. Geophys. Res.-Space, 121, 55945612, https://doi.org/10.1002/2015JA022179, 2016 b.

Scherliess, L. A. and Fejer, B. G.: Radar and satellite global equatorial F region vertical drift model, J. Geophys. Res., 104, 6829$6842,1999$.

Solomon, S. C., Woods, T. N., Didkovsky, L. V., Emmert, J. T., and Qian, L.: Anomalously low solar extremeultraviolet irradiance and thermospheric density during solar minimum, Geophys. Res. Lett., 37, L16103, https://doi.org/10.1029/2010GL044468, 2010.

Solomon, S. C., Qian, L., Didkovsky, L. V., Viereck, R. A., and Woods, T. N.: Causes of low thermospheric density during the 2007-2009 solar minimum, J. Geophys. Res., 116, A00H07, https://doi.org/10.1029/2011JA016508, 2011.

Solomon, S. C., Qian, L., and Burns, A. G.: The anomalous ionosphere between solar cycles 23 and 24, J. Geophys. Res.-Space, 118, 6524-6535, https://doi.org/10.1002/jgra.50561, 2013.

Souza, J., Brum, C., Abdu, M., Batista, I., Asevedo, W., Bailey, G., and Bittencourt, J.: Parameterized Regional Ionospheric Model and a comparison of its results with experimental data and IRI representations, Adv. Space Res., 46, 1032-1038, https://doi.org/10.1016/j.asr.2009.11.025, 2010.

Souza, J. R., Asevedo Jr., W. D., dos Santos, P. C. P., Petry, A., Bailey, G. J., Batista, I. S., and Abdu, M. A.: Longitudinal variation of the equatorial ionosphere: modeling and experimental results, Adv. Space Res., 51, 654-660, https://doi.org/10.1016/j.asr.2012.01.023, 2013.

Stoneback R. A., Heelis, R. A., Burrell, A. G., Coley, W. R., Fejer, B. G., and Pacheco, E.: Observations of quiet time vertical ion drift in the equatorial ionosphere during the solar minimum period of 2009, J. Geophys. Res., 116, A12327, https://doi.org/10.1029/2011JA016712, 2011.

Tobiska, W. K., Woods, K. T., Eparvierb, F., Viereckc, R., Floydd, L., Bouwere, D., Rottmanb, G., and White, O. R.: The SOLAR2000 empirical solar irradiance model and forecast tool, J. Atmos. Sol.-Terr. Phys., 62, 1233-1250, https://doi.org/10.1016/S1364-6826(00)00070-5, 2000. 